\title{
Obesity, Fasting Blood Sugar, Triglyceride and Physical Activity in Association With Sleep Quality in Iranian Adults in 2019
}

\section{Mazyar Haghgoo}

National Nutrition and Food Technology Research Institute

Atoosa Saidpour

National Nutrition and Food Technology Research Institute

Hakimeh Sadeghzadeh

National Nutrition and Food Technology Research Institute

Samira Rabiei ( $\sim$ samirarabiei@tyahoo.com )

National Nutrition \& Food Technology Research Institute https://orcid.org/0000-0002-3606-8969

\section{Research note}

Keywords: Sleep quality, PSQI questionnaire, Fasting Blood Sugar, Body Mass Index, Lipid profile

Posted Date: January 9th, 2021

DOI: https://doi.org/10.21203/rs.3.rs-141320/v1

License: (c) (i) This work is licensed under a Creative Commons Attribution 4.0 International License. Read Full License 


\section{Abstract}

Objectives

Sleep is an essentially biological process for health and the pattern of sleep. Poor sleep quality is increasingly recognized as a risk factor for poor health outcomes such as obesity, diabetes, and cardiovascular disease. This study aimed to investigate the association between sleep quality, body mass index (BMI) and glycemic and lipid profiles in Iranian adults in 2020. This descriptive cross-sectional study was conducted on adults aged 18-60 years from both sexes. Participants were selected from those who referred to community centers in Tehran Municipality. Three hundred and fifty-three Volunteers who had inclusion criteria entered the study by convenience sampling. Information on anthropometric measurements, Physical Activity and dietary intake were collected. Sleep quality was assessed through PSQI questionnaire. Biochemical analysis was also conducted to investigate FBS, Insulin and lipid profile.

Results

BMI had positive correlation with subscale of "sleep disturbances" and "use of sleep medication" (P-value <0.001). Physical activity had a significant negative correlation with subscales of "subjective sleep quality" and "sleep latency". FBS and TG had positive correlation with "sleep latency" and "Subjective sleep quality", respectively ( $\mathrm{p}$-value<0.05). Weak sleep quality has association with obesity, disorder of glucose and triglyceride metabolism and lower level of physical activity.

\section{Introduction}

Chronic sleep deprivation due to lifestyle changes is a common problem in modern societies (1). The prevalence of sleep disorders has been increasing over the past decades(2). Poor sleep quality has been identified as a risk factor for obesity, diabetes, and cardiovascular disease (3). Changes in sleep quality, along with changes in other lifestyle habits, such as eating, physical activity, smoking, and drinking, are likely to be potential risk factors for non-communicable diseases(4). There are some studies showing the relationship between sleep duration and glycemic (5-7) and lipid profile (8-17). Most of them have suggested that short sleep duration is associated with lower high density lipoprotein cholesterol (HDL-C) and higher triglyceride (TG) (18). Many studies have shown that short sleep duration could also be a significant risk factor for diabetes (5), while there are few studies regarding sleep quality. lyegha, et al. showed that prediabetes is positively associated with poor sleep quality (3). On the other hand, sleep quality is associated with appetite and dietary intake (1921). Poor sleep quality is also associated with severe fatigue during the day, which can reduce desire to engage in physical activities. All of these variables are associated with weight gain. Moreover, it has also documented that physical activity can improve dyslipidemia and blood glucose intolerance (22). Furthermore, poor sleep quality can increase stress levels which in turn, may lead to increase in total and LDL cholesterol and glucose serum level $(9,23)$. Considering the increasing prevalence of sleep disorders in the last decades (3) and also the lack of attention to sleep quality and its impacts on risk factors of non-communicable diseases, the current study by focusing on all sleep quality subsets was conducted on Iranian adults.

\section{Methods}

The cross-sectional study was conducted on 353 adults, aged 18-60 years from both sexes who referred to community centers in different districts in Tehran with convenience sampling method. Volunteers who were not on any kind of diet, pregnant or lactated and athlete, completed PSQI questionnaire to determine their sleep quality. To calculate BMI, weight was measured using Beurer digital scale to the nearest 100 grams, without shoes, while wearing light clothes. Height was measured to the nearest $0.5 \mathrm{~mm}$, without shoes using a non-stretch tape meter fixed to a wall. International Physical Activity Questionnaire (IPAQ) and 3- day food recalls were completed for participants. For biochemical assessments, a 
subsample of 90 participants were selected through convenience sampling method. These Participants were referred to clinic of diet therapy of Shahid Beheshti University of Medical sciences. Five cc of blood was taken after 8 to 12 hours of fasting and the serum samples were frozen immediately at $-80^{\circ} \mathrm{C}$ until assay at the end of the study. Fasting blood sugar (FBS), cholesterol, TG and HDL-c level were determined by auto analyzer, through commercial kits. Low density lipoprotein cholesterol (LDL-C) concentration was determined by the Friedewald formula (Friedewald, Levy, \& Fredrickson, 1972). ELISA method was employed to determine Insulin Level.

\section{Results}

A total of 353 people participated in this study. After excluding participants whose calorie intake was more than 800 or less than $4200 \mathrm{kcal}, 326$ people remained for the analysis. As table 1 shows, Intake of effective drugs on sleep, depression, weight and appetite, was higher in women than men, although there were not significant. Glucose and lipid profile reducing drugs, did not show any significant difference with sex. Smoking status was not also different between women and men.

Table1- Frequency of drugs intake and smoking status by sex

\begin{tabular}{|c|c|c|c|c|}
\hline & & \multicolumn{3}{|c|}{$\begin{array}{l}\text { Sex } \\
\text { Frequency (Percent) }\end{array}$} \\
\hline & & Women & men & P-value \\
\hline \multirow[t]{2}{*}{ Sedative, anti-depression drugs } & Yes & $33(86.8)$ & $5(13.2)$ & \multirow[t]{2}{*}{0.70} \\
\hline & No & $256(88.9)$ & $32(11.1)$ & \\
\hline \multirow[t]{2}{*}{ Drugs effective on weight or appetite } & Yes & $19(100)$ & $0(0)$ & \multirow[t]{2}{*}{0.10} \\
\hline & No & $270(87.9)$ & $37(12.1)$ & \\
\hline \multirow[t]{2}{*}{ Glucose reducing drugs } & Yes & $24(92.3)$ & $2(7.7)$ & \multirow[t]{2}{*}{0.54} \\
\hline & No & $265(88.3)$ & $35(11.7)$ & \\
\hline \multirow[t]{2}{*}{ Lipid profile reducing drugs } & Yes & $45(93.8)$ & $3(6.3)$ & \multirow[t]{2}{*}{0.22} \\
\hline & No & $266(87.8)$ & $34(12.2)$ & \\
\hline \multirow[t]{2}{*}{ Smoking status } & Yes & $8(50)$ & $8(50)$ & \multirow[t]{2}{*}{0.60} \\
\hline & No & $281(90.6)$ & $29(9.4)$ & \\
\hline
\end{tabular}

Table 2 shows association between all sleep quality subscales and anthropometrics, physical activity and biochemical variables by Pearson coefficient. Weight and BMI had positive correlation with subscale of "sleep disturbances" (P-value <0.001). BMI also had a significant positive correlation with subscale of "use of sleep medication". Physical activity had a significant negative correlation with subscales of "subjective sleep quality" and "sleep latency". FBS and TG had positive correlation with "sleep latency" and "Subjective sleep quality", respectively ( $\mathrm{p}$-value<0.05).

Table2- Correlation of sleep quality subscales and anthropometrics, physical activity and biochemical variables 


\begin{tabular}{|c|c|c|c|c|c|c|c|c|}
\hline \multirow[t]{3}{*}{ parameters } & $\begin{array}{l}\text { Subjective } \\
\text { sleep } \\
\text { quality }\end{array}$ & $\begin{array}{l}\text { Sleep } \\
\text { latency }\end{array}$ & $\begin{array}{l}\text { Sleep } \\
\text { duration }\end{array}$ & $\begin{array}{l}\text { Sleep } \\
\text { efficiency }\end{array}$ & $\begin{array}{l}\text { Sleep } \\
\text { disturbances }\end{array}$ & $\begin{array}{l}\text { Use of sleep } \\
\text { medications }\end{array}$ & $\begin{array}{l}\text { Day time } \\
\text { dysfunction }\end{array}$ & $\begin{array}{l}\text { Total } \\
\text { score } \\
\text { of } \\
\text { sleep } \\
\text { quality }\end{array}$ \\
\hline & $r$ & $r$ & $r$ & $r$ & $r$ & $r$ & $r$ & $r$ \\
\hline & (p-value) & $\begin{array}{l}(\mathrm{p}- \\
\text { value })\end{array}$ & $\begin{array}{l}(\mathrm{p}- \\
\text { value })\end{array}$ & (p-value) & (p-value) & (p-value) & (p-value) & $\begin{array}{l}(\mathrm{p}- \\
\text { value })\end{array}$ \\
\hline \multirow[t]{2}{*}{ Weight } & -0.27 & 0.01 & 0.02 & -0.01 & 0.18 & 0.07 & 0.09 & 0.79 \\
\hline & $(0.63)$ & $(0.79)$ & $(0.66)$ & $(0.79)$ & $(0.001) *$ & $(0.19)$ & $(0.08)$ & $(0.15)$ \\
\hline \multirow[t]{2}{*}{ BMI } & -0.03 & 0.04 & 0.04 & 0.03 & 0.19 & 0.13 & 0.006 & 0.1 \\
\hline & $(0.53)$ & $(0.44)$ & $(0.41)$ & $(0.55)$ & $(<0.001) *$ & $(0.01)^{\star}$ & $(0.91)$ & $(0.06)$ \\
\hline \multirow{2}{*}{$\begin{array}{l}\text { Physical } \\
\text { activity }\end{array}$} & -0.14 & -0.1 & 0.04 & -0.09 & 0.01 & 0.06 & -0.03 & -0.09 \\
\hline & $(0.01)^{\star}$ & $(0.05)$ * & $(0.9)$ & $(0.09)$ & $(0.85)$ & $(0.26)$ & $(0.52)$ & $(0.10)$ \\
\hline \multirow[t]{2}{*}{ FBS } & 0.006 & 0.27 & 0.09 & 0.03 & 0.16 & 0.11 & 0.08 & 0.2 \\
\hline & $(0.96)$ & $(0.02)^{*}$ & $(0.44)$ & $(0.78)$ & $(0.18)$ & $(0.36)$ & $(0.50)$ & $(0.1)$ \\
\hline \multirow[t]{2}{*}{ Insulin } & 0.08 & 0.12 & 0.08 & 0.21 & 0.18 & -0.004 & 0.04 & 0.19 \\
\hline & $(0.50)$ & $(0.31)$ & $(0.48)$ & $(0.08)$ & $(0.11)$ & $(0.97)$ & $(0.71)$ & $(0.1)$ \\
\hline \multirow[t]{2}{*}{ Cholesterol } & -0.05 & -0.08 & 0.08 & 0.13 & -0.07 & -0.29 & 0.04 & -0.04 \\
\hline & $(0.68)$ & $(0.51)$ & $(0.49)$ & $(0.28)$ & $(0.55)$ & $(0.01) *$ & $(0.74)$ & $(0.69)$ \\
\hline \multirow[t]{2}{*}{ TG } & 0.25 & 0.09 & -0.12 & -0.06 & 0.03 & -0.01 & 0.09 & 0.05 \\
\hline & $(0.03) *$ & $(0.42)$ & $(0.32)$ & $(0.61)$ & $(0.79)$ & $(0.89)$ & $(0.4)$ & $(0.64)$ \\
\hline \multirow[t]{2}{*}{ HDL-C } & 0.02 & -0.02 & 0.04 & 0.21 & -0.17 & -0.18 & -0.13 & -0.03 \\
\hline & $(0.85)$ & $(0.85)$ & $(0.72)$ & $(0.07)$ & $(0.14)$ & $(0.12)$ & $(0.28)$ & $(0.8)$ \\
\hline \multirow[t]{2}{*}{ LDL-C } & \multirow{2}{*}{$\begin{array}{l}-0.14 \\
(0.23)\end{array}$} & -0.10 & 0.11 & 0.08 & -0.02 & -0.22 & 0.05 & -0.05 \\
\hline & & $(0.38)$ & $(0.36)$ & $(0.50)$ & $(0.84)$ & $(0.06)$ & $(0.68)$ & $(0.63)$ \\
\hline
\end{tabular}

P-value $<0.05$ considered as significant

There was not any significant correlation between none of subscales of sleep quality and calorie or macronutrients intake. Data are not shown.

\section{Discussion}

Our study showed that some subscales of sleep quality are associated with FBS, TG, BMI and physical activity level. Subjective sleep quality and sleep latency were associated with both investigated biochemical factors (FBS, TG) and physical activity, although in the opposite direction. Indeed, increase in the score of those subscales is associated with increase in serum level of FBS and TG, while increase in physical activity level is associated with decrease in the score of sleep quality. The higher score of subscales of sleep quality, shows the weaker sleep quality. Although a recent metaanalysis found that exercise training resulted in improvements in sleep quality in adults with sleep problems(24), other trials have found minimal to no improvements in sleep quality due to exercise training(25). These controversial findings 
can be explained by different severity of sleep disorders and level of exercises in different studies. The association between poor sleep quality and increase in FBS and TG level in our study, is consistent with Khorasani et al's study. They found that serum levels of TG in people with poor sleep quality is higher than those with good sleep quality (26). In the current study, nothing was found between sleep quality, total cholesterol, HDL-C, LDL-C, and Insulin. This results was agreed with Zhu et al. study, that found no significant associations between PSQI score and these biochemical factors (27). Poor sleep quality may have effects on FBS and TG through some mechanisms. For example, chronic or acute sleep deprivation can increase appetite through increase in an orexigenic hormone, Ghrelin, and decrease in Leptin as an anorexigenic factor $(19,20)$. These factors may lead to weight gain that in turn, can cause increase in FBS and TG level (9, 21). Furthermore, poor sleep quality decreases glucose uptake in skeletal muscle via the hypothalamic-sympathetic nervous system axis and $\beta$-adrenergic mechanisms due to decrease in Leptin level (28). Increasing in turnover of triglycerides, inhibiting the basal and insulin-stimulated de novo lipogenesis and stimulating the oxidation of glucose and free fatty acids are of the other probable mechanisms (29). On the other hand, obesity could increase the risk of obstructive sleep apnea, which in turn, may increase metabolic impairment, including dyslipidemia(30, 31) Poor sleep quality was associated with higher BMI in the current study. Studies have reported that trends in sleep disturbances parallel trends in obesity. Despite the parallels and the related mechanisms, the association between sleep disorders and obesity is not fully understood $(32,33)$. Some authors showed that people suffering from sleep disorders are more prone to gain weight (34). Recent findings suggest that diet quality is an important mechanism that links obesity to sleep disorders(35). It is possible that some nutrients act on inflammatory hormonal responses involved in hunger-satiety mechanism and energy metabolism. We did not find any significant association between dietary intakes and sleep quality. Our finding is inconsistent with some limited evidences showing that poor sleep quality is related to higher calorie intakes and lower intakes of fish ${ }^{(36,37)}$ low energy-density fruits ${ }^{(38)}$ and vegetables ${ }^{(39-41)}$. These controversial findings may be for the reason of health status of our participants. Our participants did not have any communicable diseases like diabetes, while most of the other studies have been conducted on people with diabetes or dyslipidemia. The other probable reason may be severity of sleep disorder in our participants. The mean total score of sleep quality in our study was 6.8 , while the range of score is from 0 to 21 . It is possible that sleep quality in our participants is not such weak to be effective on dietary intake. Investigating sleep quality instead of quantity may be the other probable reason for these controversial findings. Since there was not any association between sleep quality and dietary intake, it seems that the correlation between poor sleep quality and higher BMI, is more contributable to lower physical activity than higher energy intake. Furthermore, because of the design of current study, it is not possible to determine if weight gain lead to sleep disorders or sleep disorders lead to obesity. It is suggested conducting a prospective study to assess the causality.

\section{Conclusion}

Good sleep quality plays an important role as a modulator of weight, neuroendocrine function for glucose and triglyceride metabolism and physical activity. The current study, confirmed an association between weak sleep quality and increased risk of obesity, glucose and triglyceride metabolism.

\section{Strengths and Limitations:}

One of the strong points of our study was considering all subscales of sleep quality, separately, instead of consider only total score of sleep quality. Assessment of sleep quality, instead of its quantity (sleep duration), is the other strong point of the current study. As other observational studies, there might be unmeasured confounding factors which affect the study results. For example, influences of common behavioral factors for delayed sleep onset among young people, including caffeine intake, use of electronics late at night and traditional methods to manage sleep, were not considered. Furthermore, design of this study, did not make possibility to find causality relations between investigated variables.

\section{Abbreviations}


BMI: Body Mass Index, PSQI: Pittsburgh Sleep Quality Index, FBS: Fasting Blood Sugar, HDL: High Density Lipoprotein, LDL: Low Density Lipoprotein, TG: Triglyceride, IPAQ: International Physical Activity Questionnaire, ELISA: Enzyme Linked Immunosorbent Assay

\section{Declarations}

\section{Ethics approval and consent to participate}

The present study was approved by the Ethics Committee of the National

Nutrition and Food Technology Research Institute, Iran, A signed hand-written

informed consent was obtained from each individual before data collection.

\section{Consent to publish}

Not applicable

\section{Availability of data and materials}

The raw data cannot be publicly available because of the participants' privacy and the institute regulations, as approved by the research ethics committee and has been written in consent form.

\section{Competing interests}

The authors declare that they have no competing interests.

\section{Funding}

This work was financially supported by National Nutrition and Food Technology

Research Institute "0450/1262" Faculty of Nutrition Sciences and Food

Technology, Shahid Beheshti University of Medical Sciences, Tehran, Iran.

\section{Authors' Contributions:}

M.H \& H.S collected data and conducted statistical analysis. A.S wrote the manuscript. S.R designed and supervised the study and wrote the manuscript.

\section{Acknowledgment:}

We are thankful National Nutrition and Food Science Research Institute and all of the participants in this study.

\section{References}

1. Hung H-C, Yang Y-C, Ou H-Y, Wu J-S, Lu F-H, Chang C-J. The association between self-reported sleep quality and overweight in a Chinese population. Obesity (Silver Spring, Md). 2013;21(3):486-92.

2. Paine S, Gander P, Travier N. The epidemiology of morningness/eveningness: influence of age, gender, ethnicity, and socioeconomic factors in adults (30-49 years). Journal of biological rhythms. 2006;21(1):68-76.

3. lyegha ID, Chieh AY, Bryant BM, Li L. Associations between poor sleep and glucose intolerance in prediabetes. Psychoneuroendocrinology. 2019;110:104444. 
4. Mokarrar M, Afsharmanesh A, Afshari M, Mohammadi F. Prevalence of Sleep Disorder among Medical Students in an Eastern University in Iran. Iranian Journal Of Health Sciences. 2017;5(1):49-54.

5. Gangwisch JE, Heymsfield SB, Boden-Albala B, Buijs RM, Kreier F, Pickering TG, et al. Sleep duration as a risk factor for diabetes incidence in a large U.S. sample. Sleep. 2007;30(12):1667-73.

6. Makino S, Hirose S, Kakutani M, Fujiwara M, Nishiyama M, Terada Y, et al. Association between nighttime sleep duration, midday naps, and glycemic levels in Japanese patients with type 2 diabetes. Sleep Med. 2018;44:4-11.

7. Byrne EM, Gehrman PR, Trzaskowski M, Tiemeier H, Pack Al. Genetic Correlation Analysis Suggests Association between Increased Self-Reported Sleep Duration in Adults and Schizophrenia and Type 2 Diabetes. Sleep. 2016;39(10):1853-7.

8. Bjorvatn B, Sagen IM, Øyane N, Waage S, Fetveit A, Pallesen S, et al. The association between sleep duration, body mass index and metabolic measures in the Hordaland Health Study. J Sleep Res. 2007;16(1):66-76.

9. Gangwisch JE, Malaspina D, Babiss LA, Opler MG, Posner K, Shen S, et al. Short sleep duration as a risk factor for hypercholesterolemia: analyses of the National Longitudinal Study of Adolescent Health. Sleep. 2010;33(7):956-61.

10. Kaneita Y, Uchiyama M, Yoshiike N, Ohida T. Associations of usual sleep duration with serum lipid and lipoprotein levels. Sleep. 2008;31(5):645-52.

11. Kinuhata S, Hayashi T, Sato KK, Uehara S, Oue K, Endo G, et al. Sleep duration and the risk of future lipid profile abnormalities in middle-aged men: the Kansai Healthcare Study. Sleep Med. 2014;15(11):1379-85.

12. Kong AP, Wing YK, Choi KC, Li AM, Ko GT, Ma RC, et al. Associations of sleep duration with obesity and serum lipid profile in children and adolescents. Sleep Med. 2011;12(7):659-65.

13. Lin PMD, Chang K-T, Lin Y-A, Tzeng IS, Chuang H-H, Chen J-Y. Association between self-reported sleep duration and serum lipid profile in a middle-aged and elderly population in Taiwan: a community-based, cross-sectional study. BMJ Open. 2017;7(10):e015964-e.

14. Petrov MER, Kim Y, Lauderdale D, Lewis CE, Reis JP, Carnethon MR, et al. Longitudinal associations between objective sleep and lipids: the CARDIA study. Sleep. 2013;36(11):1587-95.

15. Sabanayagam C, Shankar A. Sleep duration and hypercholesterolaemia: Results from the National Health Interview Survey 2008. Sleep medicine. 2012;13(2):145-50.

16. Shin HY, Kang G, Kim SW, Kim JM, Yoon JS, Shin IS. Associations between sleep duration and abnormal serum lipid levels: data from the Korean National Health and Nutrition Examination Survey (KNHANES). Sleep Med. 2016;24:11923.

17. Zhan Y, Chen R, Yu J. Sleep duration and abnormal serum lipids: the China Health and Nutrition Survey. Sleep Med. 2014;15(7):833-9.

18. Smiley A, King D, Harezlak J, Dinh P, Bidulescu A. The association between sleep duration and lipid profiles: the NHANES 2013-2014. Journal of Diabetes \& Metabolic Disorders. 2019;18(2):315-22.

19. Mullington JM, Chan JL, Van Dongen HP, Szuba MP, Samaras J, Price NJ, et al. Sleep loss reduces diurnal rhythm amplitude of leptin in healthy men. J Neuroendocrinol. 2003;15(9):851-4.

20. Spiegel K, Leproult R, Tasali E, Penev P, Van Cauter E. Sleep curtailment results in decreased leptin levels and increased hunger and appetite. Sleep. 2003;26:A174.

21. Taheri S, Lin L, Austin D, Young T, Mignot E. Short sleep duration is associated with reduced leptin, elevated ghrelin, and increased body mass index. PLoS Med. 2004;1(3):e62-e.

22. Lampman RM, Schteingart DE. Effects of exercise training on glucose control, lipid metabolism, and insulin sensitivity in hypertriglyceridemia and non-insulin dependent diabetes mellitus. Med Sci Sports Exerc. 1991;23(6):703-12. 
23. Harris ML, Oldmeadow C, Hure A, Luu J, Loxton D, Attia J. Stress increases the risk of type 2 diabetes onset in women: A 12-year longitudinal study using causal modelling. PLoS One. 2017;12(2):e0172126-e.

24. Yang $\mathrm{P}, \mathrm{Ho} \mathrm{K}$, Chen $\mathrm{H}$, Chien $\mathrm{M}$. Exercise training improves sleep quality in middleaged and older adults with sleep problems: a systematic review. J Physiother. 2012;58:157-63.

25. Tworoger S, Yasui Y, Vitiello M. Effects of a yearlong moderate-intensity exercise and a stretching intervention on sleep quality in postmenopausal women. Sleep. 2003;26:830-6.

26. Khorasani M, Mohammadpoorasl A. The association between sleep quality and metabolic factors and anthropometric measurements. Biotechnology and Health Sciences. 2016;3(4):25-31.

27. Zhu B-Q, Li X-M, Wang D, Yu X-F. Sleep quality and its impact on glycaemic control in patients with type 2 diabetes mellitus. International Journal of Nursing Sciences. 2014;1(3):260-5.

28. Minokoshi Y, Toda C, Okamoto S. Regulatory role of leptin in glucose and lipid metabolism in skeletal muscle. Indian J Endocrinol Metab. 2012;16(Suppl 3):S562-8.

29. Harris R. Direct and Indirect Effects of Leptin on Adipocyte Metabolism. Biochimica et biophysica acta. $2013 ; 1842$.

30. Tahrani AA. Obstructive sleep apnoea in diabetes: Does it matter? Diabetes and Vascular Disease Research. 2017;14(5):454-62.

31. Said S, Mukherjee D, Whayne TF. Interrelationships with metabolic syndrome, obesity and cardiovascular risk. Current Vascular Pharmacology. 2016;14(5):415-25.

32. Beccuti G, Pannain S. Sleep and obesity. Curr Opin Clin Nutr Metab Care. 2011;14(4):402-12.

33. Dempsey JA, Veasey SC, Morgan BJ, O'Donnell CP. Pathophysiology of sleep apnea. Physiol Rev. 2010;90(1):47-112.

34. Muscogiuri G, Barrea L, Annunziata G, Di Somma C, Laudisio D, Colao A, et al. Obesity and sleep disturbance: the chicken or the egg? Crit Rev Food Sci Nutr. 2019;59(13):2158-65.

35. Hargens TA, Kaleth ES, Edwards, Butner KL. Association between sleep disorders, obesity, and exercise: A review. Nature and Science of Sleep. 2013;5:27-35.

36. Del Brutto OH, Mera RM, Ha JE, Gillman J, Zambrano M, Castillo PR. Dietary fish intake and sleep quality: a population-based study. Sleep Med. 2016;17:126-8.

37. Katagiri R, Asakura K, Kobayashi S, Suga H, Sasaki S. Low intake of vegetables, high intake of confectionary, and unhealthy eating habits are associated with poor sleep quality among middle-aged female Japanese workers. J Occup Health. 2014;56(5):359-68.

38. Kong F, Li H, Xu G, Ying Y, Gong Q, Zhao J, et al. Association of Dietary Behaviors and Sleep Quality: Results from the Adults Chronic Diseases and Risk Factors Survey of 2015 in Ningbo, China. Int J Environ Res Public Health. 2018;15(9).

39. Grandner MA, Kripke DF, Naidoo N, Langer RD. Relationships among dietary nutrients and subjective sleep, objective sleep, and napping in women. Sleep medicine. 2010;11(2):180-4.

40. Brondel L, Romer MA, Nougues PM, Touyarou P, Davenne D. Acute partial sleep deprivation increases food intake in healthy men. Am J Clin Nutr. 2010;91(6):1550-9.

41. St-Onge MP. Sleep-obesity relation: underlying mechanisms and consequences for treatment. Obes Rev. 2017;18 Suppl 1:34-9. 